\title{
A importância da Resolução n²16 nas Unidades de Alimentação e Nutrição para diminuição das DTAS no Brasil
}

\author{
The importance of Resolution $\mathbf{n}^{0} 216$ in the Food and Nutrition Units to reduce DTAS in Brazil \\ La importancia de la Resolución n²16 en las Unidades de Alimentación y Nutrición para reducir \\ DTAS en Brasil
}

Recebido: 22/11/2021 | Revisado: 29/11/2021 | Aceito: 30/11/2021 | Publicado: 11/12/2021

\author{
Hellem Chrystian Ribeiro da Silva \\ ORCID: https://orcid.org/0000-0001-9903-7994 \\ Centro Universitário Fametro, Brasil \\ E-mail: hellemribeiro-17@hotmail.com \\ Francisca Marta Nascimento de Oliveira Freitas \\ ORCID: https://orcid.org/0000-0002-0044-0925 \\ Centro Universitário Fametro, Brasil \\ E-mail: Francisca.freitas@fametro.edu.br \\ Rebeca Sakamoto Figueiredo \\ ORCID: https://orcid.org/0000-0002-9819-8099 \\ Centro Universitário Fametro, Brasil \\ E-mail: rebeca.figueiredo@fametro.edu.br
}

\begin{abstract}
Resumo
Introdução: Este artigo visa mostrar a importância da Resolução 216/04 nas unidades de alimentação e nutrição com o uso do checklist para fazer a avaliação das normas higiênico sanitários nesses estabelecimentos. Objetivo Geral: elucidar a importância da resolução n²16 nas Unidades de Alimentação e Nutrição para diminuição das DTAS no Brasil. Metodologia: Para a organização de dados coletados foi usado uso da metodologia dedutiva. Resultados $e$ Discussão: Esta RDC foi criada pela ANVISA no intuito de diminuir as taxas de doenças transmitidas por alimentos (DTAS) no Brasil, as DTAS são doenças transmitidas por alimentos contaminados por microrganismos como bactérias, vírus entre outros, com isso viu-se a necessidade da criação do manual de boas práticas na manipulação dos alimentos para padronizar uma espécie de roteiro a ser seguidos nesses estabelecimentos visando a saúde dos clientes e dos manipuladores. Também teremos uma breve descrição do manual de boas práticas de fabricação de alimentos que visa estabelecer normas nos locais de fabricação de qualquer tipo de produto do setor alimentício, além disso será citado sobre como diminuir as DTAS e também como identificar essas doenças de acordo com os sintomas apresentados pelas pessoas que fizeram a ingestão desses alimentos contaminados por microrganismos. Conclusão: concluiu-se que a RCD 216/04 é uma importante lei para o controle e prevenção das DTAS nas unidades de alimentação e nutrição (UAN). Sua maior finalidade é a implantação de padrões higiênicos sanitários a serem seguidos nas UAN para que com isso não haja contaminação alimentar.
\end{abstract}

Palavras-chave: UAN; ANVISA; Higiênico-sanitárias; RDC 216.

\begin{abstract}
Introduction: This article aims to show the importance of Resolution 216/04 in food and nutrition units with the use of the checklist to assess the hygienic and sanitary standards in these establishments. General Objective: elucidate the importance of resolution $\mathrm{n}^{\circ} 216$ in the Food and Nutrition Units to reduce DTAS in Brazil. Methodology: For the organization of collected data, the use of deductive methodology was used. Results and Discussion: This RDC was created by ANVISA in order to reduce the rates of foodborne illnesses (DTAS) in Brazil. STDs are diseases transmitted by food contaminated by microorganisms such as bacteria, viruses, among others. need to create a manual of good practices in food handling to standardize a kind of script to be followed in these establishments, aiming at the health of customers and handlers. We will also have a brief description of the manual of good food manufacturing practices, which aims to establish standards at the manufacturing sites of any type of product in the food sector, and it will also be mentioned on how to reduce DTAS and also how to identify these diseases according to symptoms presented by people who made the ingestion of these foods contaminated by microorganisms. Conclusion: it was concluded that RCD 216/04 is an important law for the control and prevention of STDs in food and nutrition units (UAN). Its main purpose is the implementation of hygienic sanitary standards to be followed in the UAN so that there is no food contamination.
\end{abstract}

Keywords: UAN; ANVISA; Hygienic-sanitary; RDC 216. 


\begin{abstract}
Resumen
Introducción: Este artículo tiene como objetivo mostrar la importancia de la Resolución 216/04 en las unidades de alimentación y nutrición con el uso de la lista de verificación para evaluar los estándares higiénicos y sanitarios en estos establecimientos. Objetivo general: dilucidar la importancia de la resolución $\mathrm{n}^{\circ} 216$ en las Unidades de Alimentación y Nutrición para reducir la DTAS en Brasil. Metodología: Para la organización de los datos recolectados se utilizó el uso de metodología deductiva. Resultados y Discusión: Este RDC fue creado por ANVISA con el fin de reducir las tasas de enfermedades transmitidas por alimentos (DTAS) en Brasil. Las ETS son enfermedades transmitidas por alimentos contaminados por microorganismos como bacterias, virus, entre otros. prácticas en el manejo de alimentos para estandarizar una especie de guión a seguir en estos establecimientos, con el objetivo de la salud de los clientes y manipuladores. También tendremos una breve descripción del manual de buenas prácticas de fabricación de alimentos, que tiene como objetivo establecer estándares en los sitios de fabricación de cualquier tipo de producto del sector alimentario, y también se mencionará cómo reducir DTAS y también cómo Identificar estas enfermedades de acuerdo a los síntomas que presentan las personas que realizaron la ingestión de estos alimentos contaminados por microorganismos. Conclusión: se concluyó que la RCD 216/04 es una ley importante para el control y prevención de las ETS en las Unidades de Alimentación y Nutrición (UAN). Su objetivo principal es la implementación de las normas higiénicas sanitarias a seguir en la UAN para que no haya contaminación de los alimentos.
\end{abstract}

Palabras clave: UAN; ANVISA; Higiénico-sanitário; RDC 216.

\title{
1. Introdução
}

No Brasil, estima-se que, de cada cinco refeições, uma é feita fora de casa, na Europa duas em cada seis e, nos EUA, uma em cada duas. Esses números indicam que ainda pode haver um grande aumento e desenvolvimento dos locais que produzem refeições para consumo imediato no país. Tais estabelecimentos incluem unidades de produção de porte e tipos de organização diferentes entre si, como restaurantes comerciais, restaurantes de hotéis, serviços de motéis, coffee shops, buffets, lanchonetes, cozinhas industriais, fast food, catering e cozinhas hospitalares (Cunha, Magalhães \& Bonnas, 2013)

Com isso viu-se a necessidade da criação de normas higiênico-sanitárias especificas para esses locais como a RESOLUÇÃO No 216 de 15 de setembro de 2004. Esta RDC 216/04 tratasse de um conjunto de normas, que foram retiradas inicialmente do manual de boas práticas e do Procedimento de Operação Padronizado (POP). As Boas Práticas de Manipulação de Alimentos são as práticas de organização e higiene necessárias para garantir alimentos seguros envolvendo todas as etapas: seleção dos fornecedores, compra, recebimento, pré-preparo, preparo, embalagem, armazenamento, transporte, distribuição e exposição à venda para o consumidor final (Manual de Boas Práticas na Manipulação de Alimentos, 2019).

Já o Procedimentos Operacionais Padronizados - POP descreve clara e objetivamente as operações rotineiras e específicas nas Unidades de Alimentação e Nutrição (UAN), contribuindo para garantia da segurança das refeições e a promoção das Boas Práticas. Um dos procedimentos importantes para se evitar a contaminação dos alimentos é a higienização adequada de superfícies, uma vez que entram em contato com os alimentos e são potentes veiculadores de micro-organismos (Implantação de um Procedimento Operacional Padronizado em uma Unidade de Alimentação e Nutrição em Salvador - BA. 2014).

$\mathrm{Na}$ (UAN) essa RDC é de vital importância, pois com á mesma tivemos a implementação de processos para á melhoria de qualquer manuseio de produtos de relacionados a alimentos (Ministério da Saúde, 2004).

Essa resolução dentro de uma unidade de alimentação tem como um dos objetivos mostrar formas adequadas de como o local deve ser composto como é citado no trecho 4.1.5 que as instalações devem ser abastecidas de água correte e dispor de conexões com rede de esgoto ou fossa séptica. Quando presentes, os ralos devem ser sifonados e as grelhas devem possuir dispositivos que permitam seu fechamento (Ministério da Saúde, 2004).

Por tanto esta resolução é de vital importância pra as unidades de alimentação pós com ela podemos ter uma melhoria no funcionamento dessas unidades e fazendo assim com que diminua a taxa de DTAS (Ministério da Saúde, 2004). 
Também ser descrito nesse projeto as boas práticas de fabricação de alimentos para assim evitar as doenças transmitidas por alimentos, a grande importância da diminuição das DTAS e o quanto é importante a função da RCD 216/04 nas unidades de alimentação e nutrição para a qualidade dos produtos do setor de alimentos (Ministério da Saúde, 2014).

A Organização Mundial de Saúde (OMS) afirma que as doenças transmitidas por alimentos são uma grande preocupação de saúde pública global e calcula-se que, a cada ano, provoquem o adoecimento de uma a cada 10 pessoas e 33 milhões de anos de vida perdidos, Além do mais, DTA podem ser letais, principalmente em crianças menores de 5 anos, ocasionando cerca de 420 mil mortes. Na região das Américas, as infermidades diarreicas são a causa de $95 \%$ das doenças transmitidas por alimentos. (Ministério da Saúde, 2021)

De acordo com o Centers for Disease Control and Prevention (CDC), centro de vigilância de doenças dos Estados Unidos, calcula-se que de cada 6 americanos 1 fiquei doente e que 128 mil são hospitalizados e 3.000 morrem a cada ano por doença transmitida por alimentos (DTA).

Já no Brasil, a vigilância epidemiológica das DTA (VE-DTA) acompanha os surtos de DTA e os casos das doenças definidas em legislação específica. De acordo com dados do Sistema de Informação de Agravos de Notificação (Sinan), em média são informados mais de 700 mil surtos de doenças transmitidas por alimentos, sendo 13 mil infectados e 10 óbitos (Ministério da Saúde, 2021).

Para identificarmos a importância da aplicação da RDC n²16/04 na melhoria da qualidade dos alimentos produzidos em unidades de alimentos e nutrição necessitamos entender sobre algumas coisas para assim evitar a contaminação dos alimentos e diminuir as DTAS (Ministério da Saúde, 2004)

Doenças transmitidas por alimentos (DTAS) são aquelas causadas pela ingestão de alimentos e/ou água contaminados. Existem mais de 250 tipos de DTAS no mundo, sendo que a maioria delas são infecções causadas por bactérias e suas toxinas, vírus e outros parasitas' (Ministério da Saúde, 2021)

É considerado surto de DTAS quando duas ou mais pessoas apresentam doença ou sintomas semelhantes após ingerirem alimentos e/ou água da mesma origem, normalmente em um mesmo local. Para doenças de alta relevância, como Botulismo \& Cólera, somente o relato de um caso já é considerado surto', (Ministério da Saúde, 2021).

As Doenças transmitidas por alimentos, mais popularmente conhecidas como DTA, são originadas pela ingestão de alimentos e/ou água contaminados. De acordo com a ANVISA existem mais de 250 DTA e a maior parte são infecções causadas por bactérias e suas toxinas, vírus e parasitas (Sirtoli \& Comarella, 2018).

“No Brasil, embora o número de notificações de DTA seja crescente, a subnotificação e falhas nas etapas de investigação comprometem a geração de informações que orientem as pesquisas laboratoriais dos possíveis agentes envolvidos o que têm contribuído com o elevado número de processos não conclusivos”' (Dias, Bernarde \& Zuccoli, 2011).

'Como as doenças transmitidas por alimentos (DTA) podem ter várias causas, não há um quadro clínico específico. No entanto, os sintomas mais comuns são: náuseas, vômitos, dores abdominais, diarreia, falta de apetite, febre '. (Ministério da Saúde, 2021)

Os sintomas deveram se manifesta de acordo com cada tipo de infecção e vários microrganismos criam os mesmos sintomas, o que prejudica na hora de fazer o diagnóstico clínico um correto. Podem ocorrer também infecções extra intestinais em vários órgãos e sistemas como no fígado que pode ocasionar Hepatite A, terminações nervosas periféricas podendo ocasionar botulismo, má formação congênita (Toxoplasmose) dentre outros (Ministério da Saúde, 2021).

“'As Boas Práticas de Fabricação (BPF) representam uma importante ferramenta da qualidade para o alcance de níveis adequados de segurança dos alimentos, e sua adoção é um requisito da legislação vigente e faz parte dos programas de garantia da qualidade do produto final"' (Manual de Boas Práticas de Fabricação, 2015). 
Na unidade de alimentação e nutrição (UAN) é necessário a utilização de uma lista chamada de checklist para avalia as conformidades e não conformidades do local. ''É utilizado para criação do checklist algumas normas e resoluções como a RDC 216/04 a RDC 273/02 o manual de boas práticas e manipulação de alimentos o POP e a portaria $n^{\circ} 5$ de 2013 com o objetivo de avaliar as normas higiênico sanitárias da (UAN) e com isso diminuir focos de DTAS nessas locas" (Cecon \& Comarella, 2015).

O objetivo deste estudo foi mostrar a importância da RESOLUÇÃO 216/04 nas unidades de alimentação e nutrição com o uso do checklist para fazer a avaliação das normas higiênico-sanitários nesses estabelecimentos.

\section{Metodologia}

O estudo foi realizado com coleta de dados a partir de fontes secundárias, por meio de levantamento bibliográfico e baseado na experiência vivenciada por autores. Para a organização de dados coletados foi usado uso da metodologia dedutiva, pois segundo Marconi e Lakatos (2010) o processo dedutivo parte de uma constatação geral para uma específica, do processo maior para o menor.

Para o levantamento da literatura foram utilizadas Livros, Revistas, Diretrizes da Sociedade Brasileira, artigos em sites como SCIELO (Scientific Eletronic Library), PubMed (Serviço da National Library of Medicine).

Para a busca dos artigos, foram utilizados os descritores: Clostridium butolinum, Resolução no 216 de 15 de setembro de 2004, vigilância sanitária e Higienização dos alimentos e suas combinações nas línguas inglesas, espanhola.

Na seleção inicial foram selecionados artigos entre 2010 a 2020, 35 publicações; no SciELO foram encontrados 20; Pubmed, 11; Medline, 2, e teses, 4. Assim sendo, 40 publicações compõem o presente estudo, resultantes de pesquisas primárias quantitativas, qualitativas e estudos teóricos. Os artigos encontrados resumem-se em língua portuguesa, inglesa e espanhola. 
Figura 1. Fluxograma detalhando cada etapa do processo de seleção de artigos para a revisão.

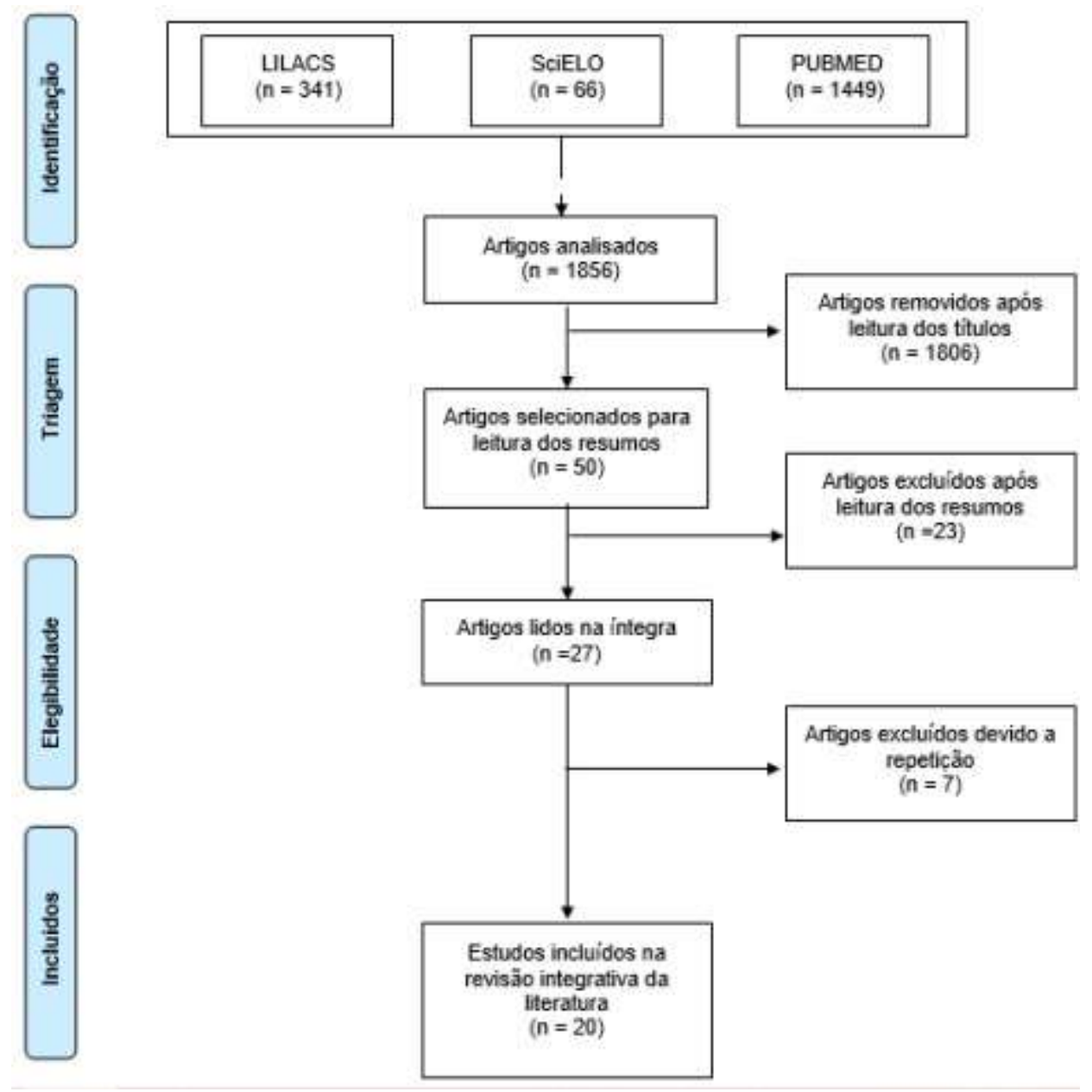

Fonte: Cavalcante et al. (2021).

\section{Resultados e Discussão}

Foi utilizado o checklist para averiguar as normais higiênico sanitárias e com isso constatou-se que no local que foi realizado o estudo, avaliou a temperatura dos congeladores do estabelecimento que estavam de acordo com as normais exigidas pela agência de vigilância sanitária. Porém a temperatura na hora do transporte do pescado não estava conforme de acordo com a agência de vigilância sanitária. Já no seguindo quadro também foi utilizado como modo de avaliação o checklist, para avaliar as conformidades e não conformidades de acordo com a RDC 216 e 275 que avaliou as condições físicas e higiênico sanitárias das escolas avaliadas, que mostram a escola A, com 17 conformidades e 8 não conformidades, escola B, 18 conformidades e 7 não conformidades, escola C, com 16 conformidades e 9 não conformidades. E no terceiro quadro foi analisado as temperaturas preconizadas pela RDC 216 e CVS 5/2013 que regulamentam a distribuição de alimentos quentes a temperatura $\geq 60^{\circ} \mathrm{C}$ por, no máximo, seis horas e de preparações frias até $10^{\circ} \mathrm{C}$ por, no máximo, quatro horas (Anvisa, 2004 ; CVS, 2013), e com a análise dos resultados foi proposto aos gerentes do estabelecimento, ações para serem desenvolvidas pra melhoria e qualidades dos serviços oferecidos no local (Quadro 1). 
Quadro 1 - Resultados

\begin{tabular}{|c|c|c|}
\hline Autor(es) & Ano de Publicação & Resultados \\
\hline Monique Letícia Coutinho & 18 de outubro de 2020 & $\begin{array}{l}\text { Para o pescado, verificou-se conformidade para a técnica de } \\
\text { congelamento, onde estes estavam armazenados em freezer } \\
\text { horizontal em temperatura abaixo de }-20^{\circ} \mathrm{C} \text {, por no mínimo } 24 \text { horas, } \\
\text { além do fato do pescado não ser descongelado. A documentação do } \\
\text { fornecedor de pescado do estabelecimento também estava correta, o } \\
\text { local apresentava, inclusive, uma cópia do alvará sanitário do } \\
\text { fornecedor. Porém, o item recebimento sob congelamento em } \\
\text { temperatura igual ou inferior a }-18^{\circ} \mathrm{C} \text { mostrou-se não conforme. Ao } \\
\text { aferir a temperatura do pescado recebido, este se encontrava a }-5^{\circ} \mathrm{C} \text {, } \\
\text { além disso, o local não dispunha de termômetro para a aferição dos } \\
\text { produtos e correto controle da temperatura. Stoffel e Piemolini- } \\
\text { Barreto (2018) também verificaram a ausência de termômetro no } \\
\text { restaurante oriental estudados pelas autoras. Miranda e Baião (2011) } \\
\text { verificaram falhas no acondicionamento do pescado cru, durante a } \\
\text { preparação, além do recongelamento deste. }\end{array}$ \\
\hline $\begin{array}{l}\text { Karla Cássia Nunes } \\
\text { e } \\
\text { Karlenny Kristianny Gomides } \\
\text { Silva }\end{array}$ & 25 de janeiro de 2014 & $\begin{array}{l}\text { Foram avaliadas três escolas da rede pública de Rianápolis-GO } \\
\text { através da aplicação de um checklist que avaliou as condições físicas } \\
\text { e higiênico sanitárias das cozinhas e dos manipuladores de alimentos. } \\
\text { Os resultados do checklist foram mostrados através de } \\
\text { conformidades e não conformidades de acordo com as RDC } \\
216 / 2004 \text { e } 275 / 2002 \text { (Tabela } 1,2,3) \text {. A escola A, apresentou } 17 \\
(68 \%) \text { de conformidade e } 8(32 \%) \text { de não conformidades; a escola B, } \\
18(72 \%) \text { conformidade e } 7(28 \%) \text { de não conformidades e a escola } \\
\text { C, } 16(64 \%) \text { de conformidade e } 9(36 \%) \text { de não conformidades. }\end{array}$ \\
\hline $\begin{array}{l}\text { Nara Vanessa dos Anjos } \\
\text { Barros, } \\
\text { Adolfo Pinheiro de Oliveira, } \\
\text { Mateus da Conceição Araújo, } \\
\text { Iraildo Francisco Soares, } \\
\text { Neyeli Cristine da Silva. }\end{array}$ & abr. mai. jun. 2019 & $\begin{array}{l}\text { Após a tabulação dos dados, os resultados foram analisados segundo } \\
\text { as temperaturas preconizadas pela Resolução RDC n }{ }^{\circ} 216 \text { de } 15 \text { de } \\
\text { setembro de } 2004 \text { e CVS } 5 / 2013 \text {, que regulamentam a distribuição de } \\
\text { alimentos quentes a temperatura } \geq 60^{\circ} \mathrm{C} \text { por, no máximo, seis horas e } \\
\text { de preparações frias até } 10^{\circ} \mathrm{C} \text { por, no máximo, quatro horas } \\
\text { (ANVISA, 2004; CVS, 2013). Após a análise dos resultados, foram } \\
\text { disponibilizados aos gerentes dos restaurantes relatórios com os } \\
\text { resultados e sugestões de ações a serem desenvolvidas para melhoria } \\
\text { da qualidade dos serviços. }\end{array}$ \\
\hline
\end{tabular}

Fonte: Autores.

\section{Conclusão}

Por tanto concluiu-se que a RCD 216/04 é uma importante lei para o controle e prevenção das DTAS nas unidades de alimentação e nutrição (UAN). Sua maior finalidade é a implantação de padrões higiênicos sanitários a serem seguidos nas UAN para que com isso não haja contaminação alimentar. Esta RDC também preconiza as condições higiênicos sanitárias com equipamentos e utensílios que são utilizados na fabricação de alimentos.

Juntamente com a RDC 216/04 também temos a RDC 275/02 que foram utilizadas na criação do checklist para formas de avaliação das conformidades e não conformidades de acordo com as normas estabelecidas nestas RDC para assim evitar contaminação alimentar com isso diminuindo as taxas de doenças transmitidas for alimentos (DTAS).

\section{Referências}

Aguiar, A. M. M., Batista, B. V. A., Santos, I. H. V. S., \& Oliveira, L. M. L. (2017). Avaliação da eficácia de uma intervenção sobre as boas práticas de higiene em três lanchonetes de uma escola particular em Porto Velho-RO. 
Almeida, J. C., Paula, C. M. S., Svoboda, W. K., Lopes, M. O., Pilonetto, M. P., Abrahão, W. M., \& Gomes, E. C. (2013). Perfil epidemiológico de casos de surtos de doenças transmitidas por alimentos ocorridos no Paraná, Brasil. Revista, Ciências Biológicas e da Saúde, Londrina, 34(1), 97-106.

Alves, D. C., \& Bueno, S. M. (2018). Revisão do manual de boas práticas de fabricação e procedimentos operacionais padronizados de uma indústria de aromas. Revista cientifica, 1(1).

Barros, N. V. A., Oliveira, A. P., Araújo, M. C., Soares, I. F., \& Silva, N. C. (2019). Avaliação da qualidade higiênico-sanitária em restaurantes self-service do município de Picos-PI. Revista interdisciplinar Centro Universitario Uninovafapi, 12(2).

Cecon, T. S. F., \& Comarella, L. (2015). Check list de avaliação higiênico-sanitária para unidades de alimentação e nutrição. Revista Saúde e Desenvolvimento, 84

Costa, J. N. P., Santos, V. V. M., Silva, G. R., Moura, F. M. L., Gurgel, C. A. B., \& Moura, A. P. B. L. (2013). Condições higiênico-sanitárias e físicoestruturais da área de manipulação de carne in natura em minimercados de Recife (PE), Brasil. Arq. Inst. Biol., São Paulo, 80(3).

Coutinho, L. M. (2020). Padronização de procedimentos higienicossanitários de restaurantes de culinárias japonesa. Hig. Alimentar, $34(291)$, e1005.

Cunha, F. M. F., Magalhães, M. B. H., \& Bonhas, D. S. (2013). Desafios da gestão da segurança dos alimentos em unidades de alimentação e nutrição no Brasil: uma revisão. Senac, 1(24).

Cunha, R. Q. (2020). Análise microbiológica de saladas de frutas comercialidas no municipio de pouso alegre - MG. Revista Higiene Alimentar, 34 (291).

Dantas, A. M., \& Marques, R. V. L. (2021). Implementação das boas práticas de fabricação em indústria processadora de goma de tapioca. Revista Higiene Alimentar, 35(293), e1061.

Faúla, L. L., Soares, A. C. C., \& Dias, R. S. (2014). Panorama dos surtos de doença de transmissão alimentar (DTA) ocorridos em Minas Gerais, Brasil do periodo de 2010 a 2014. Revista de saúde pública do SUS/ MG, 3(1), 84.

Freire, C. E. C. A., \& Mendes, R. R. C. (2020). Revista Higiene Alimentar, 34 (291).

Junior, F. P. A., Lima, B. T. M., Alves, T. W. B., \& Menezes, M. E. S. (2019). Fatores que propiciam o desenvolvimento de Staphylococcus aureus em alimentos e riscos atrelados a contaminação: uma breve revisão. Revista de Ciências Médicas e Biológicas, 18(1), 89-93.

Lakatos, E. M., \& Marconi, M. De A. (2010). Fundamentos de metodologia científica: Técnicas de pesquisa. (7ª ed.): Atlas.

Lombardi, E. C., Bonnas, D. S., Jardim, F. B. B., Oliveira, K. A., \& Silva, R. T. (2020). Atuação dos profissionais de saúde na investigação de suspeitas de surtos de DTA's nos hospitais de Uberlândia, Minas Gerais, Segur.Aliment. Nutr., Campinas, v. 27, p. 1-9. e020005.

Machado, R. L. P., Dutra, A. S., \& Pinto, M. S. V. (2015). Boas Práticas de Fabricação (BPF). Embrapa Agroindústria de Alimentos Rio de Janeiro, RJ.

Marciel, A. R., Oliveira, J. B. H. S. G., Meireles, N. M. S., Silva, I. S., Nascimento, O. M., Silva, L. L., \& Almeida, B. S. (2016). Verificação das boas práticas de fabricação em panificadoras da cidade de Marabá, Pará, Brasil. A.R.Macielet al.,Scientia Plena, 12(06).

Marinho, A. G., Oliveira, G. S., Lima, J. L., Lopes, W. M. A., Nunes, G. A., \& Nunes, M. G. A. (2015). Perfil Epidemiológico das Doenças Transmitidas por Alimentos e Seus Fatores Causais na Região da Zona da Mata Sul de Pernambuco. Revista UNOPAR Cient Ciênc Biol Saúde.

Ministerio da Saúde. (2021). O que são doenças transmitidas por alimentos. https://antigo.saude.gov.br/saude-de-a-z/doencas-transmitidas-por-alimentos

Ministerio da Saúde. Resolução 216 de 15 de setembro de 2004.

Moro, M. F., Bem, A. R., Weise, A. D., Reis, C. C. C., \& Schmidt, C. A. P. (2015). Avaliação das boas práticas de fabricação em uma panificadora: Um estudo de caso. Revista espacios 36 (09)

Neumann, L., \& Fassina, P. (2016). Verificação de boas práticas em uma unidade de alimentação e nutrição de um município do vale do taquari - rs. Revista UNINGÁ Review. 26(1), 13-22.

Pittelkow, A., \& Bitello, A. R. (2014). A higienização de manipuladores de uma unidade de alimentação e nutrição (uan). Revista Destaques Acadêmicos, 6(3), CCBS/UNIVATES.

Santos, R. M. S., Gouveia, D. S., Rocha, A. P. T., Silva, W. M., \& Lins, A. D. F. (2015). Avaliação de restaurante universitário por meio do regulamento técnico de boas práticas para serviços de alimentação. Revista Verde (Pombal - PB - Brasil), 10(2), 26 - 32.

Sirtoli, D. B., \& Caramella, L. (2018). O papel da vigilância sanitária na prevenção das doenças transmitidas por alimentos (DTA). Revista Saúde e Desenvolvimento, 12(10).

Souza, D. R., Leal, B. A. F., \& Zuccoli, P. C. (2011). A importância do processo de investigação na elucidação de surtos de Doenças Transmitidas por Alimentos (DTA). Belo Horizonte, MG, 01(02).

Souza, A. O., Passos, E. V. B., Gonçalves, M. I. A., Coelho, R. L. L., \& Silva, C. S. (2021). Perfil higiênico-sanitário de um restaurante comercial no interior baiano. Research, Society and Development, 10(2), e46410211870.

Torres, F. P. S. (2020). Revista Higiene Alimentar, 34 (291): e1039. 